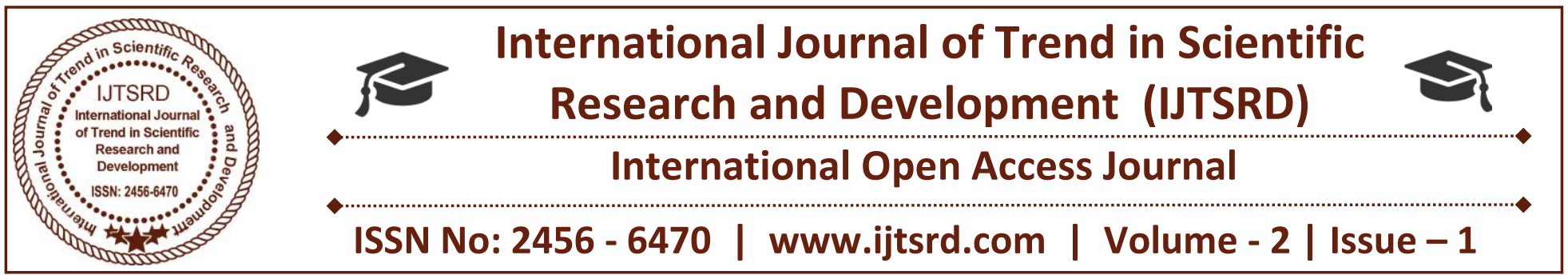

\title{
Assessment of the Extent of the Knowledge of Anganwadi Workers regarding Maternal, Child Nutrition and Health and Problems Faced during Job Fulfillment: A Study of Urban and Rural Areas of Jaipur District of Rajasthan
}

\author{
Anamika Choudhary \\ Research Scholar, Department of Home Science, \\ Mahatma Jyoti Rao Phoole (MJRP) University \\ Jaipur, Rajasthan, India
}

\author{
Shilpi Sharma \\ Assistant Professor, Department of Home Science, \\ Mahatma Jyoti Rao Phoole (MJRP) University \\ Jaipur, Rajasthan, India
}

\begin{abstract}
Anganwadi worker is community based frontline workers. The central points for the delivery ICDS services at community levels to children below six years of age, pregnant women, nursing mothers and adolescent girls. The Anganwadi worker should be self sufficient to deliver these activities in prevention and control of malnutrition, spread awareness among vulnerable at grass root level by providing services at doorstep. The present study was conducted to find out the level of knowledge and practices of anganwadi workers regarding various maternal and child health $\&$ nutrition and problems faced by them during their job. For present study 180 anganwadi centers of urban and rural areas were selected randomly.
\end{abstract}

For knowledge and practices assessment questionnaire was constructed. One mark was given for a correct response, while no mark was given for a wrong response of unanswered question.

Majority of the respondents $36.67 \%$ were between 31 40 years while mostly $44 \%$ percent respondents were matriculated.

Anganwadi workers has high level of knowledge for breast feeding (73.64\%), complementary feeding (71.29\%), and diarrhoea management (71.33\%) whereas middle level of knowledge for supplementary feeding $(65.87 \%)$ and growth monitoring $(66.66 \%)$.
Inadequate honorarium, excess work load and infrastructure at the centers were main problems faced by them. It can conclude that the quality of knowledge among anganwadi workers for their job profile was sufficient. Anganwadi workers had theoretical knowledge about concept of growth monitoring however in practical skill they were poor. For efficiently working anganwadi workers needs proper infrastructure for anganwadi centers, should be ensued by government or by community.

Keywords; Anganwadi worker, Knowledge of anganwadi worker, Problem of anganwadi worker, ICDS services

\section{INTRODUCATION}

The Integrated Child Development Services (ICDS) scheme was conceived in 1975 . The Scheme aims to improve the nutritional and health status of vulnerable groups including pre-school children, pregnant women and nursing mothers through a package of services including supplementary nutrition, pre-school education, immunization, health check-up, referral services and nutrition and health education. The program provides an integrated approach for converging basic services through community-based Anganwadi workers. 
The Anganwadi workers (AWWs) are the community based voluntaries frontline workers of the ICDS programme selected from the community; she assumes a pivotal role due to close and continuous contacts with the beneficiaries. They represent the concerns of the state within the community or cluster of households.

AWW is the central points for the delivery of services at community levels to children below six years of age, pregnant women, nursing mothers and adolescent girls. AWWs help the children to get into the right from the pre-school age. AWW educates to family especially mothers to ensure effective health and nutrition care, early recognition and timely treatment of ailments.

By virtue of her position in the community, the Anganwadi worker has more chances to interact and to educate the mothers. For that the Anganwadi worker should have basic knowledge of child care activities. Among all functions of AWW, growth monitoring and supplementary feeding are directly linked with the prevention and control of malnutrition in children. These two activities are independent activities carried out by the Anganwadi worker in relation to promotion of health of the vulnerable group. After about 45 years of work of AWW, no major change accrued at maternal and child health.

AWW play a vital role to enhance the overall development of the infant and women. But after a long period of time in Indian health state of vulnerable group hardly improved. Infant mortality rate, malnourishment, low birth weight, unhygienic living condition, lacking of awareness in beneficiaries are still gigantic issue which are making questions for work credibility of anganwadi workers.

Although AWWs are key player to enhance health and nutritional status at grass root level, but recent studies show that they are less capable of providing recommended Maternal and Child Health $(\mathrm{MCH})$ services to the deprived group of population. [1][2]. though government is spending lot of money on ICDS programme, impact is very ineffective. In India nutritional and health status of vulnerable groups are still very deprived after 40 years of ICDS launched.

Most of the study concentrated on the nutritional and health status of the beneficiaries of ICDS. Less focus has been shifted over to assess the knowledge and awareness among AWW regarding recommended ICDS programmer, who are actually the main resource person. The output or the ICDS scheme is to a great extent dependant on the profile of the key functionary i,e. the AWW, her qualification, experience, skills, attitude., training etc. AWWs form the bedrock on which performance of ICDS programme squarely rests. The Anganwadi worker should be self sufficient to deliver these activities in prevention and control of malnutrition, spread awareness among vulnerable at grass root level by providing services at doorstep.

\section{OBJECTIVE}

1. To assess the extent of the knowledge of anganwadi workers regarding various maternal and child nutrition and health issues.

2. To investigate the problems faced by anganwadi worker during fulfillment of job responsibilities.

\section{METHODOLOGY}

The present study was conducted in Jaipur district. For present study 9 blocks of Jaipur district were selected. Selection ratio of anganwadi centers was 2:1(rural 2: urban 1), as anganwadi centers number are more concentrated in rural areas. From each rural and urban block 20 anganwadi centers (AWCs) were selected. Total anganwadi center of jaipur is 4002, of which total 180 anganwadi centers were selected under which both rural and urban areas were covered. From each anganwadi, anganwadi worker, one beneficiary pregnant woman or lactating mother and one adolescent girl was selected randomly. Therefore total 180 anganwadi worker, 180 pregnant women or lactating mother and 180 adolescent girls were studied.

The study was based on primary data. For the collection of data, which were used interview schedule and observation are major techniques. Data was collected by personal visits made to Anganwadi centers. To analyze the data collected from field survey, simple statistical tools as tabulation and percentage method used for the result.

\section{DESCRIPTION OF THE TOOL USED}

As pre- designed standardized test for knowledge, and practices assessments a questionnaire was constructed for the present study. Anganwadi workers profile, their basic information were collected like her age, 
education, caste and experience etc. For knowledge assessment, a scoring system was developed.

The knowledge assessment score for each AWW was calculated which was based on the response to a questionnaire containing 38 questions. The questionnaire was so designed as to contain question on every aspect of services provided through the Anganwadi center. It included questions on 5 different aspects of functioning of AWWs regarding maternal and child nutrition practices and physical health (i.e. breast feeding, complementary feeding, supplementary feeding, diarrhoea management and growth monitoring)

One mark was given for a correct response, while no mark was given for a wrong response of unanswered question. The knowledge of AWWs was scored out of 38 questions. Question numbers were very for 5 different aspect of functioning of AWWs. All the correct answers of 180 AWWs for individual aspect were added to find the score of that individually aspect.

This score was converted to percentage. These percentages were classified as qualitative classification given by [3] to find out the knowledge level of anganwadi worker and beneficiaries. Information about AWWs was expressed as mean \pm S.D. values or percentage.

\section{RESULT AND DISCUSSION}

Table-1 shows the socio-demographic profile of AWWs. It indicates that majority of them is young adults. Mean age of Anganwadi workers was38.27 and S.D 2.73. It is clear that a majority of the respondents 36.67 percent (66) were in the age group of 31 years to 40 years (figure 1). A majority of 44 percent (79) respondents were matriculated, 29.44 percent (53) respondents were secondary and 15.56 percent (28) respondents were graduates. Only 11.11percent (20) had post-graduation degree (figure 2). However other cast categories are also present. All the respondents were belongs to the area where the Anganwadi center is located and had a permanent residence in the same area. All the respondents had received job training.

With regard to the mean (year) work experience was 12.011 and S.D \pm 5.23.majority of the respondents 33.89 percent (61) had more than 15 years (figure 3 ). There was not any respondent who had more than 40 years of work experience in their career. With regard to All the respondents were belongs to the area where the Anganwadi center is located and had a permanent residence in the same area.

In present study the knowledge of anganwadi workers regarding various aspects of maternal and child nutrition and physical health was assessed to out find the proficiency of anganwadi workers for their job profile.

Table-2 Details of knowledge of AWWs Regarding 5 aspect of maternal \& child nutrition and physical health issues, knowledge is very essential for implementation of ICDS program in a better way. Table- 2 and figure 4 shows the details of knowledge of AWWs regarding maternal \& child nutrition and physical health. By good knowledge of these 5 aspects of maternal \&child nutrition and physical health only then an AWW can work efficiently. It was observed that they high have level of knowledge for breast feeding $(73.64 \%)$, complementary feeding (71.29\%), and diarrhoea management (71.33\%). In present investigation it was found that AWWs had middle level of knowledge for supplementary feeding $(65.87 \%)$ and growth monitoring $(66.66 \%)$. Overall AWWs scored $70.13 \%$ in knowledge assessment regarding maternal \& child nutrition and physical health.

Table-3 Problems Faced by anganwadi workers, while performing different types of functions it was obvious that AWWs supposed to face variety of problems. Table-3 and figure 5 show the problems faced by selected Anganwadi workers. 80 percent respondents were complained of inadequate honorarium, they had the problem of getting honorarium at proper time. 50 percent respondents were complained of excessive record maintenance and mostly all respondents (70\%) were complained of work overload as they have to assist for other health programs apart from their anganwadi related work like in pulse polio program etc. Only 40 percent complained of lack of help and support from beneficiaries' family and from community. 30 percent respondents were complained inadequate supervision and 50 percent respondents were complained about it supply that ration was not directly supply at their Anganwadi centers. 30 percent respondents were complained about other problems like Furniture, toys, weighing machine, inch tape, utensils, iodine checks kit, black board, thermometer and IEC material etc were not found at all centers. 
International Journal of Trend in Scientific Research and Development (IJTSRD) ISSN: 2456-6470

Such materials are not found in required quantity at present but not in working condition and these $30 \%$ centers. At $40 \%$ centers these material were efficiency of anganwadi workers was reduced.

Table 1: Socio-demographic profile of AWWs

\begin{tabular}{|c|c|c|c|}
\hline \multicolumn{2}{|c|}{ Socio-demographic details of Anganwadi workers } & \multirow{2}{*}{\begin{tabular}{|l|l|}
$\begin{array}{l}\text { Anganwadi workers } \\
\text { (numbers) }\end{array}$ \\
S.D $( \pm 2.73)$ year \\
\end{tabular}} & \multirow[t]{2}{*}{$\begin{array}{l}\text { Anganwadi workers } \\
\text { (percentage \%) }\end{array}$} \\
\hline Mean age (year) & 38.27 years & & \\
\hline \multirow[t]{4}{*}{ Age group } & 20-30 years & \pm 38 & $21.11 \%$ \\
\hline & $31-40$ years & \pm 66 & $36.67 \%$ \\
\hline & $41-50$ years & \pm 55 & $30.55 \%$ \\
\hline & $51-60$ years & \pm 21 & $11.67 \%$ \\
\hline \multirow[t]{5}{*}{ Educational status } & Illiterate & - & - \\
\hline & $1-9$ class & \pm 53 & $29.44 \%$ \\
\hline & 10-12 class & \pm 79 & $43.89 \%$ \\
\hline & Graduate & \pm 28 & $15.56 \%$ \\
\hline & Post Graduate & \pm 20 & $11.11 \%$ \\
\hline \multirow[t]{5}{*}{ Caste } & Scheduled Caste & \pm 30 & $16.67 \%$ \\
\hline & Scheduled Tribe & \pm 15 & $8.33 \%$ \\
\hline & Other backward Caste & \pm 50 & $27.78 \%$ \\
\hline & General & \pm 75 & $41.66 \%$ \\
\hline & Minority & \pm 10 & $5.56 \%$ \\
\hline \multirow[t]{2}{*}{ Training Status } & Trained & \pm 180 & $100 \%$ \\
\hline & Untrained & - & - \\
\hline $\begin{array}{l}\text { Work Experience } \\
\text { Mean(years) }\end{array}$ & 12.01years & S.D $( \pm 5.23)$ & \\
\hline \multirow[t]{4}{*}{ Work experience } & $1-5$ years & \pm 41 & $22.78 \%$ \\
\hline & 6-10years & \pm 50 & $27.78 \%$ \\
\hline & 11-15years & \pm 28 & $15.56 \%$ \\
\hline & More than 15years & \pm 61 & $33.89 \%$ \\
\hline \multirow[t]{2}{*}{ Residence status } & Anganwadi centers area & \pm 180 & $100 \%$ \\
\hline & $\begin{array}{l}\text { Outside anganwadi centers } \\
\text { area }\end{array}$ & - & - \\
\hline
\end{tabular}


International Journal of Trend in Scientific Research and Development (IJTSRD) ISSN: 2456-6470

Table 2: Details of Knowledge of AWWs regarding 5 aspect of maternal \& child nutrition and physical health

\begin{tabular}{|l|c|c|l|}
\hline Types of service & $\begin{array}{c}\text { Total } \\
\text { responses }\end{array}$ & Percent knowledge & Knowledge level \\
\hline Breast feeding & 1193 & 73.64 & High level \\
\hline Complementary feeding & 770 & 71.29 & High level \\
\hline Supplementary feeding & 830 & 65.87 & Middle level \\
\hline Diarrhoea management & 1284 & 71.33. & High level \\
\hline Growth monitoring & 720 & 66.66 & Middle level \\
\hline Total & 4797 & 70.13 & High level \\
\hline
\end{tabular}

Table 3: Problems faced by anganwadi workers

\begin{tabular}{|l|l|}
\hline Type of problem & Percentage of anganwadi worker \\
\hline Inadequate honorarium & $80 \%$ \\
\hline Excessive record maintenance & $50 \%$ \\
\hline Work overload & $70 \%$ \\
\hline Lack of support from community & $40 \%$ \\
\hline Inadequate supervision & $30 \%$ \\
\hline Ration supply related & $50 \%$ \\
\hline Infrastructure related & $80 \%$ \\
\hline Other problems & $30 \%$ \\
\hline & \\
\hline
\end{tabular}

Fig 1: Shows age status of anganwadi workers

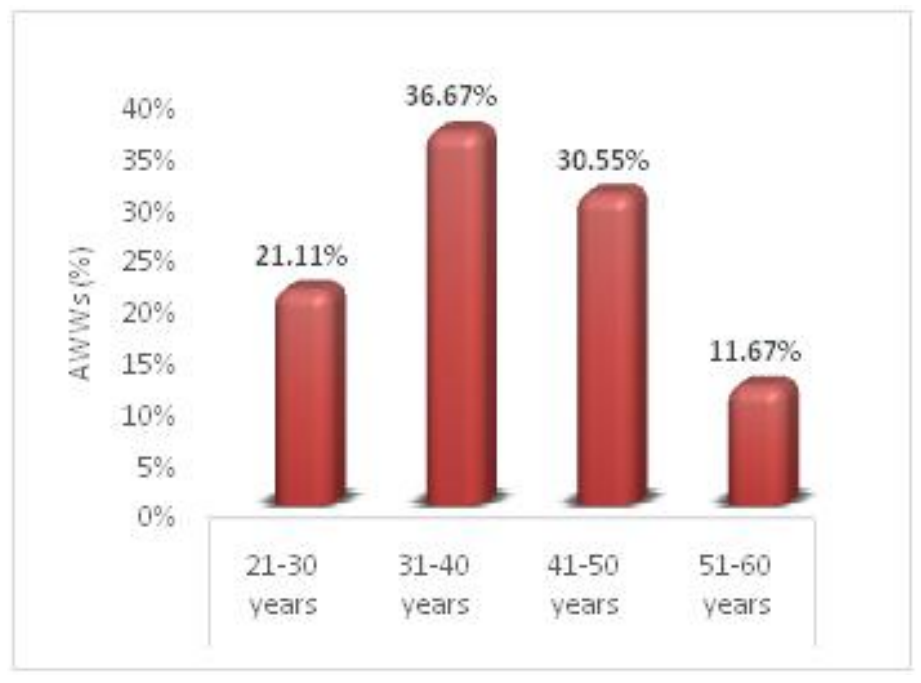

Fig 2: Shows educational status of anganwadi workers

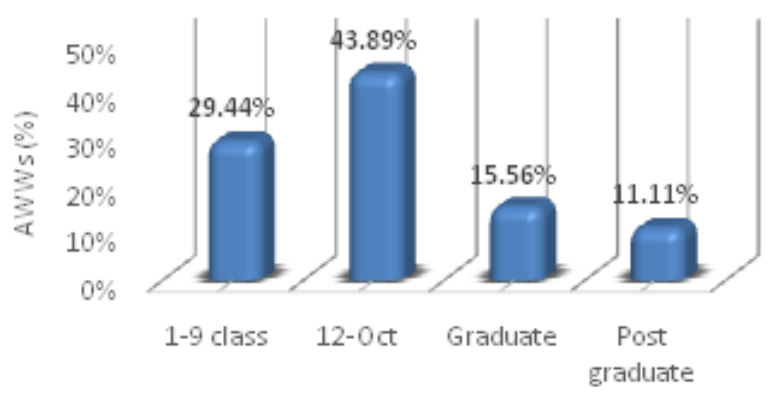

educational Status 
Fig. 3: Shows work experience of anganwadi workers

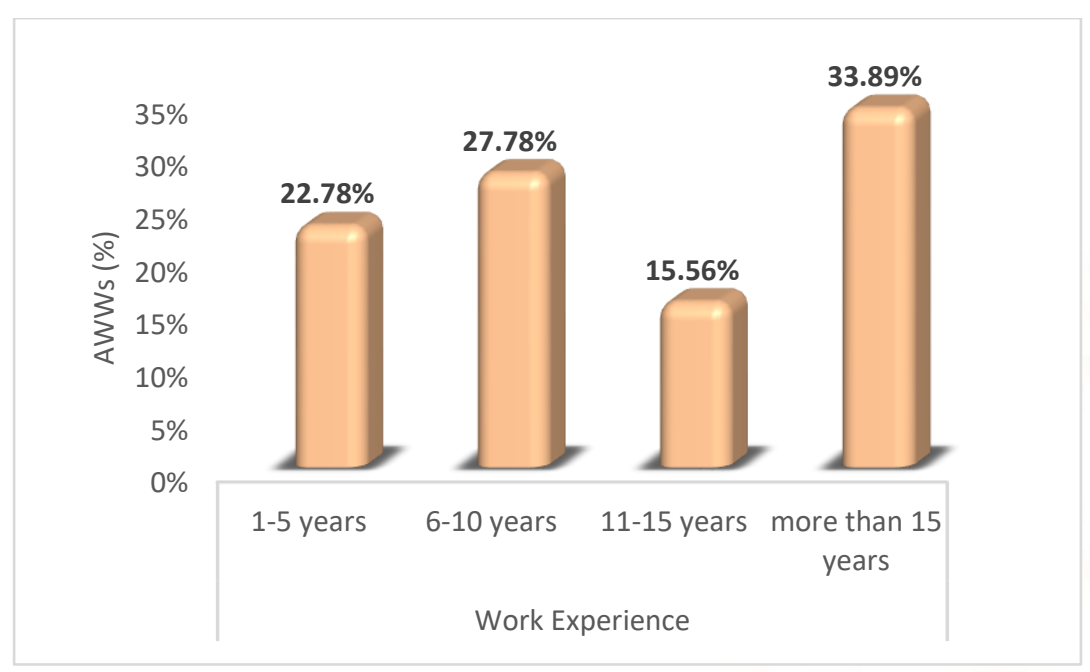

Fig. 4: Shows knowledge of anganwadi workers for different aspects of health and nutrition

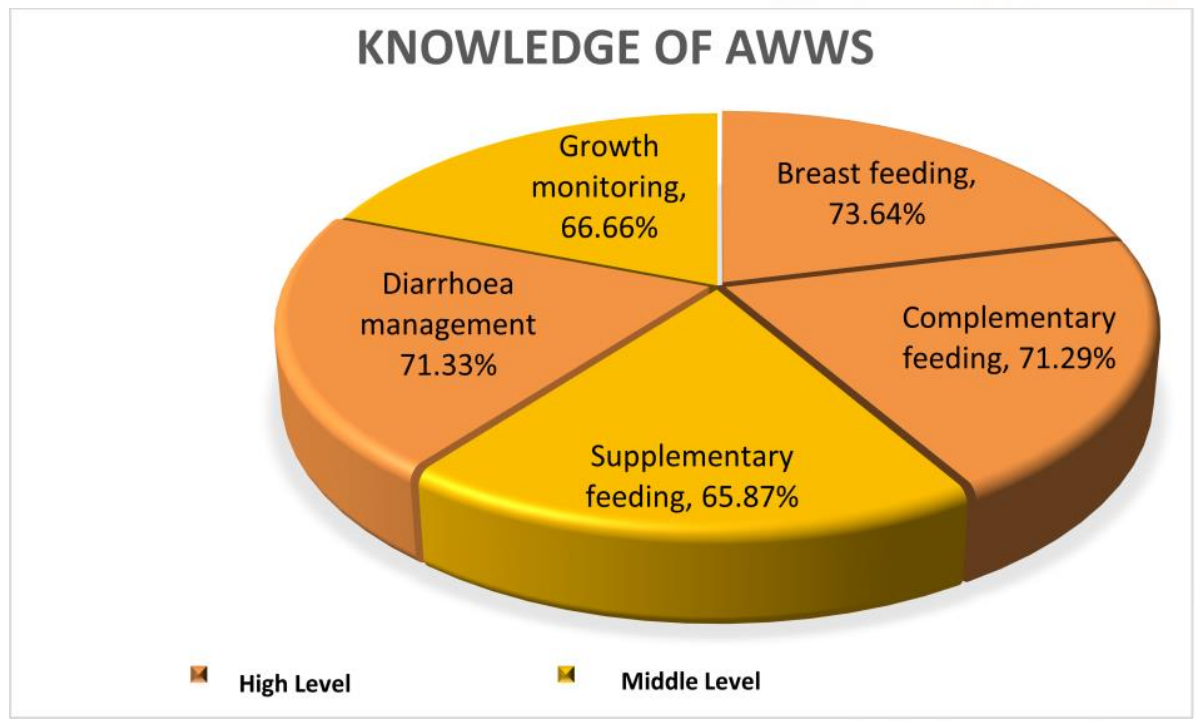

Fig. 5: Shows problem faced by anganwadi workers PERCENTAGE

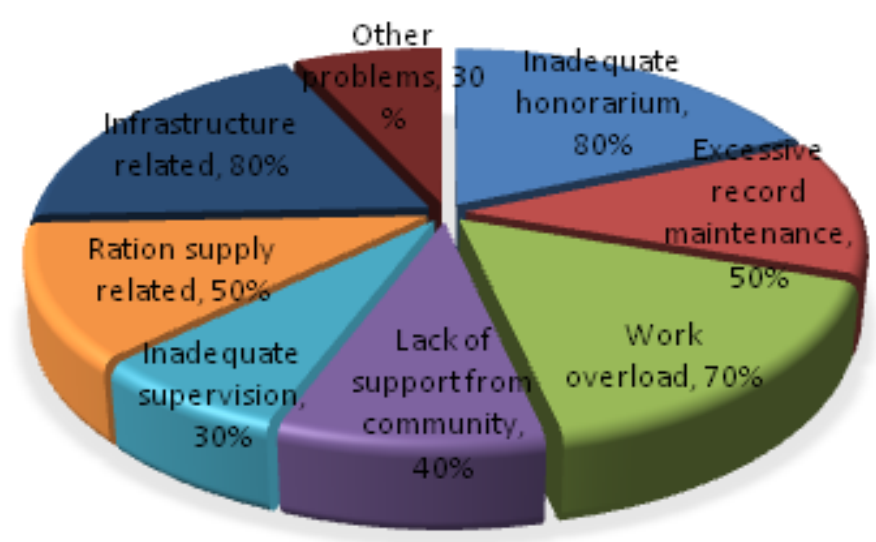




\section{DISCUSSION}

The Integrated Child Development Services (ICDS) scheme is the largest programme for promotion of maternal and child health and nutrition not only in India in but in the whole world.

In present study i.e. workers $66(36.67 \%)$ were in the age group of 31-40 yrs. Programme Evaluation Officer (PEO) Study [4], on the integrated child development services project found that $82 \%$ of the Anganwadi workers belonged to the age group 18-25 years. [5], Reported that 50\% of AWWs were more than 35 years of age. [6] Also reported that critical assessment of AWCs observed that $32 \%$ of AWWs were below 30 yrs age. Three decades of ICDS, a comprehensive assessment of the programme at national level undertaken by National Institute of Public co-operation and Child Development, [7] made an observation that $30 \%$ of AWWs were in age group of 25-35 years. A study was conducted by [2], to assess the knowledge of anganwadi workers and their problems faced an urban block of ICDS. It was found that Maximum number of workers, 11(39.28\%) were in the age group of $41-50 \mathrm{yrs}, 7(25 \%)$ each in the age group of 31-40 years and more than 50 years. Lowest number i.e., $3(10.7 \%)$ belonged to the age group of 20-30 year, similar age group of anganwadi worker was found on present study.

In present study, $43.89 \%$ of AWWs educational levels were between matriculate which is consistent with many other studies. A study was conducted by [2], to assess the knowledge of anganwadi workers and their problems faced an urban block of ICD. In this study Almost half $(53.57 \%)$ of AWWs were matriculate. $16.5 \%$ AWWS were intermediate only $3.57 \%$ AWWs were post- graduate.

World Food Programme, India [8], a pilot Project Funded by USAID observed wide variations in respect of educational level of Anganwadi workers. While 25\% were educated below Standard V. 5\% were graduates; the modal educational level being Standard VIII. These studies support present study and it concluded that maximum AWW were at least matriculate.

With regard to the work experience majority of the respondents 33.89 percent (61) had more than 15 years of experience. A similar study conducted by
[2], shows that maximum number of workers $(82.14 \%)$ had an experience of more than 10 years.

As per the findings of present study, AWWs have high knowledge about breast feeding, complementary feeding and diarrhoea management where as for supplementary feeding and growth monitoring had middle level of knowledge. Overall AWWs scored $70.13 \%$ in knowledge assessment. Similarly [2], investigate that AWWs have best knowledge about the component of nutrition and health education $(77.14 \%)$ while least about supplementary nutrition $(29.46 \%)$.

Another study made in Purmandal block shows that in spite of the fact that most $(92.5 \%)$ of the Anganwadi workers were trained, it was found that performance as well as awareness among Anganwadi workers regarding the importance of growth charts and growth monitoring was not satisfactory [9].

A study was conduct by [10] found that only $11.8 \%$ Anganwadi workers could define fever. More than 90\% workers correctly knew about the stages related to vitamin A deficiency and dosage schedule for children;' $59 \%$ knew the total number of IFA (Iron, Folic Acid) tablets to be given to a pregnant mother.

In present investigation problems felt by AWWs were mainly inadequate honorarium $(80 \%)$, work overload $(70 \%)$, infrastructure $(80 \%)$, and ration supply related $(50 \%)$. Similar problems felt by AWWs in the study of [2], in this study main problem were inadequate honorarium $(75 \%)$ and excessive record maintenance.

A study was conduct by [11], has similar result that $56.7 \%$ are complained of inadequate salary while only $16.7 \%$ complained of lack of logistic supply related problems. About half of the Anganwadi workers complained that they have Infrastructure related problem like inadequate space for displaying NonFormal Preschool Education (NFPSE) posters or other posters related to nutrition and health education, space is not available for conducting recreational activities like outdoor activities, irritation by animals entering into Anganwadi centre. Forty three percent of workers not happy because of overload of work. And $40 \%$ of the workers complained for excessive record maintenance as they have to assist for other health programmes apart from their Anganwadi related work like in pulse polio programme, vitamin A distribution programme conducted by Municipal Corporation. 


\section{CONCLUSION:}

Most of the selected AWWs were from age group3140 yrs., intermediate, trained, experienced, having knowledge of $70.13 \%$ in their daily functions at AWCs.

The quality of knowledge among AWWs for their job profile was sufficient. Their knowledge regarding some components of childcare, maternal care and diarrhoea management is mostly adequate as they do what they have learnt and their knowledge is retained. Along with previous studies and on the basis of present finding it concluded that AWWs had theoretical knowledge about concept of growth monitoring however in practical skill they were poor. This indicate that they might be facing a lot of problem in maintain growth charts. Anganwadi workers were not aware of the importance of growth chart instead they were maintaining the growth charts as per the requirement of their job profile only.

Problems felt by them were mainly due to inadequate honorarium and excess work load and infrastructure. Therefore, timely increments in honorarium should be considered. Functioning of AWCs were also depends on infrastructure of center. Therefore a proper infrastructure for AWC should be ensued by government or by community.

\section{REFERENCES:}

1. Davey A. Datta U. the functioning of anganwadi centers in urban slums of delhi. delhi: national institute of health and family welfare, (2004).

2. Thakare M.M, Kuril B.M, Doibale M.K, Goel N, Knowledge of anganwadi workers and their Problems in an urban icds block, Journal of medical college chandigarh, (2011)1(1): 15-19.

3. Jain j, Sexena R; dissertation pre service teacher education programme-a review study regarding the utility of microdessection study of trainee's aptitude, MJRP collage jaipur,2011, 33.

4. Programme evaluation organization, planning commission, govt. of India,(POC) Study N 0.12, evaluation report on the integrated child development services project (1976-78) (-1982).

5. Khan Z, Hasan J, a profile of anganwadi workers in jawan, block of district aligarh, uttar Pradesh , indian Journal of community medicine, (1992)5862.
6. Seema TN, performance of anganwadi centers in kerala: an evaluation experiment to develop a model centre with community participation discussion paper no. 28, kerala research programmers on local level development studies, Tiruvananthapuram, (2001) ISBN no.81-8762130-3.

7. Three decades of icds a appraisal, national institute of public cooperation and child development, 5, siriii institutional area, hauz khas, new delhi-110016.

8. World food programme india, the food aid arm of the united nation, adolescent girls in tribal integrated child development services, a pilot project funded by USAIDI wfp.newdelhi@

9. Manhas, Shashi, Annpurna Dogra and Seema Devi, reflection of integrated child development services (ICDS) in implementation of Services at bishnah and purmandal block,jammu, studies on home and community science, (2012) 6(1): 27-32.

10. Chattopadhyay D, knowledge and skills of anganwadi workers in hooghly district, west bengal, indian journal of community medicine, (2004-09).

11. Jena, prasanti; knowledge of anganwadi worker about integrated child development services (ICDS): a study of urban blocks in sundargarh district of odisha, dissertation, NIT rourkela (2013). 